\title{
GROWTH OF LUCERNE
}

\author{
R. H. M. LANGER \\ Lincoln College, Canterbury
}

THERE CAN BE few other forage plants which have stimulated a greater volume of research work than lucerne. Although part of the reason for this sustained interest may be its great antiquity as a fodder plant, for lucerne has a documented history of over 2,000 years, of greater importance has undoubtedly been its ability to produce high yields of good quality forage, especially under dry conditions.

Despite this considerable amount of attention, there are very many aspects of this plant which continue to challenge the scientist and which pose serious problems to the farmer. The management of lucerne for optimum yield is probably the most important of these partially solved questions, largely because of the almost infinite number of ways in which soil, climate, cutting and grazing intensity and frequency can interact. In view of this enormous variability it would be quite impossible to devise simple and unalterable recipes for lucerne farming. What is more rewarding and of greater lasting value is to understand how this plant grows and how best to use its advantages and minimize its deficiencies, based on a firm knowledge of the principles involved. This paper will therefore trace the life-history of lucerne, and then attempt to draw from it conclusions which can be applied to management in the field.

\section{SEEDLING GROWTH}

As the seed germinates, the young root and shoot appear through the seed coat. The shoot consists initially of the two cotyledons which unfold, and this is followed by the appearance of the first, simple leaf which is borne on a slender stalk. Next, the first trifoliate leaf emerges, also supported by a slender stem, with later leaves appearing at successively higher nodes. In contrast to other legumes, the lucerne seedling is a fairly tall, slender and delicate structure, which requires careful management if it is to survive and establish. 
The most important aspect of early seedling growth concerns the buds which occur in the axil of each cotyledon, the simple leaf and the trifoliate leaves, because it is from these buds that the plant branches out and develops what subsequently will become the crown. Each bud as it grows out to form a shoot will give rise to further buds in the axil of leaves and bracts, so that gradually a collection of such sites accumulates from which the plant regenerates after cutting.

From this brief survey of seedling growth a number of important considerations may be derived. The first concerns the time when newly sown lucerne may be grazed without harming the plant. To graze too early would clearly endanger the young seedling and especially the buds on which further growth depends. On the other hand, grazing at an early stage could be beneficial, because it may encourage the plant to produce more branches and buds. A further point is that lucerne should be given every opportunity to develop a deep, strong root system, which will enable it to thrive under the typically dry conditions in which it outyields other pasture plants. In practice, this means grazing when the stand is about 4 in. high following sowing in the spring. At the risk of causing some damage, it is advisable to graze hard and fairly close to the ground. This will tend to check weeds, whereas lucerne with its deep roots, which by that time will have penetrated some 10 to 12 in., should come away quickly and suppress its competitors. After this grazing, lucerne should be spelled until flower buds are visible on the stems.

The fact that lucerne may easily be dominated by weeds during its establishment highlights the fact that at this stage it is a poor competitor. The main effect appears to be competition for light, and this has been demonstrated in many experiments in which young lucerne plants were grown at different levels of light intensity. Table 1 shows typical results which illustrate how the plant is affected by shading.

Reducing the light intensity depressed growth very considerably. Equally significant in this context, however, are the relatively greater depression of root growth as shown in the declining root/ top ratios and the absence of root nodules in shaded plants. Projected to a field scale, these results indicate that lucerne must be protected from weed competition for light and that every step should be taken to prepare a clean seed-bed. Pure sowings are obviously the safest approach, because a sown companion grass 
TABLE 1: EFFECT OF REDUCED LIGHT INTENSITY ON LUCERNE SEEDLINGS

(after Pritchett and Nelson, 1951)

\begin{tabular}{cccc}
\hline $\begin{array}{c}\text { Glasshouse } \\
\text { Light }\end{array}$ & $\begin{array}{c}\text { Total } \text { Dry W eight } \\
\text { ( } \mathbf{g} \text { ) } \\
\text { (7 plants) }\end{array}$ & $\begin{array}{c}\text { Root/Top } \\
\text { Ratio }\end{array}$ & $\begin{array}{c}\text { N o. of N odules } \\
\text { (7 plants) }\end{array}$ \\
\hline 100 & 18.7 & 0.9 & 895 \\
27 & 11.5 & 0.7 & 117 \\
14 & 6.6 & 0.6 & 9 \\
9 & 2.1 & 0.3 & 0 \\
5.5 & 1.0 & 0.2 & 0 \\
\hline
\end{tabular}

or crop could easily deprive lucerne seedlings of light and other essential factors. The main effects of competition show up, first, in suppressed root growth and thus the danger that lucerne may be prevented from expressing its potential for drought resistance, and, secondly, in reduced nodulation despite all efforts to inoculate and correct soil acidity. A further point that arises is that lucerne does not establish well from oversowing, unless the resident vegetation has been checked. Different methods of doing this, including the use of herbicides, are at present being investigated at Lincoln.

\section{ROOT DEVELOPMENT}

The most obvious feature of lucerne roots is the depth to which they penetrate. The young plant develops a taproot which is branched near the top, but these branches also grow deeply into the soil. In the first season of growth, the roots may reach a depth of 5 to $6 \mathrm{ft}$, and 9 to $10 \mathrm{ft}$ have been measured in plaants two years old. A single mature plant has been estimated to occupy $94 \mathrm{cu} . \mathrm{ft}$ of soil. The structure of the root system reflects soil conditions. Thus, in dry, porous soils there are fewer branches but very many more fine rootlets than in moist soils. As far as management is concerned, there are two functions of. the roots which have to be emphasized. In the first place they absorb water and nutrients to sustain the growth of the plant and, because of their great depth, they enable the plant to withstand long dry spells and to outyield grasses and clovers in droughty soils. In addition to this, the roots of lucerne are important through their ability to provide the plant with materials necessary for growth when it has been cut or grazed and before enough 
leaf has been formed for photosynthesis to occur on an adequate scale. From this it follows that the underground parts of lucerne have to be cared for as an insurance against poor growth of the tops. The effects of cutting frequency on the roots are shown in Table 2. In this experiment, lucerne growing in the field was cut at 1 in. either 7 (severe) on 3 (lenient) times between early December and mid-April. The weight of roots and the diameter of the taproot were then assessed by taking plug samples.

TABLE 2: TOTAL DRY WEIGHTS OF ROOTS AND MEAN DIAMETER OF TAPROOTS

(Keoghan, 1966)

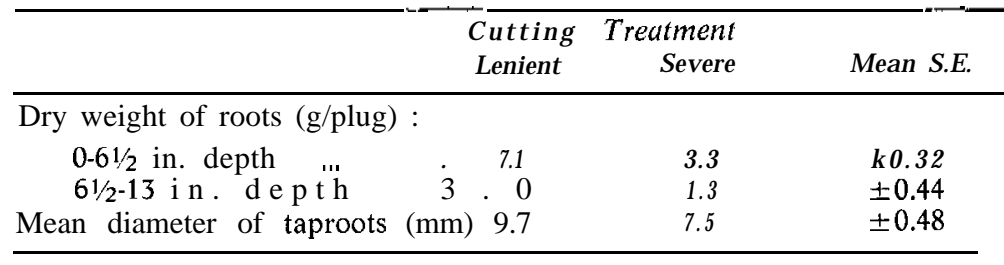

Severe cutting reduced root weight, especially in the top layer of soil, and the diameter of the taproots was also adversely affected. Subsequent production of plants treated in this manner reflects these differences in root growth. This has been confirmed in many experiments in which severely treated lucerne has been shown to recover very slowly.

\section{GROWTH OF THE MATURE PLANT}

Apart from the effects on the root system, the key to successful lucerne management is, to fit the cutting or grazing regime closely to the natural growth pattern of the plant. It is important to remember that any plant which has to stand up to repeated cutting or grazing should be able to recover quickly after each defoliation. Grasses are extremely well designed in this respect, except when they are beginning to flower, for the growing points of the tillers and a reasonable amount of leaf escape being removed and thus regrowth is immediate and sustained. In lucerne the growing points are removed when the plant is cut, so that recovery growth depends on the availability of sites from which new shoots can arise. 
These sites are buds situated either in the axil of stubble leaves or on the so-called crown of the plant.

The crown is a very complex and ill-defined part of the plant. Initially it is made up of the first few branches

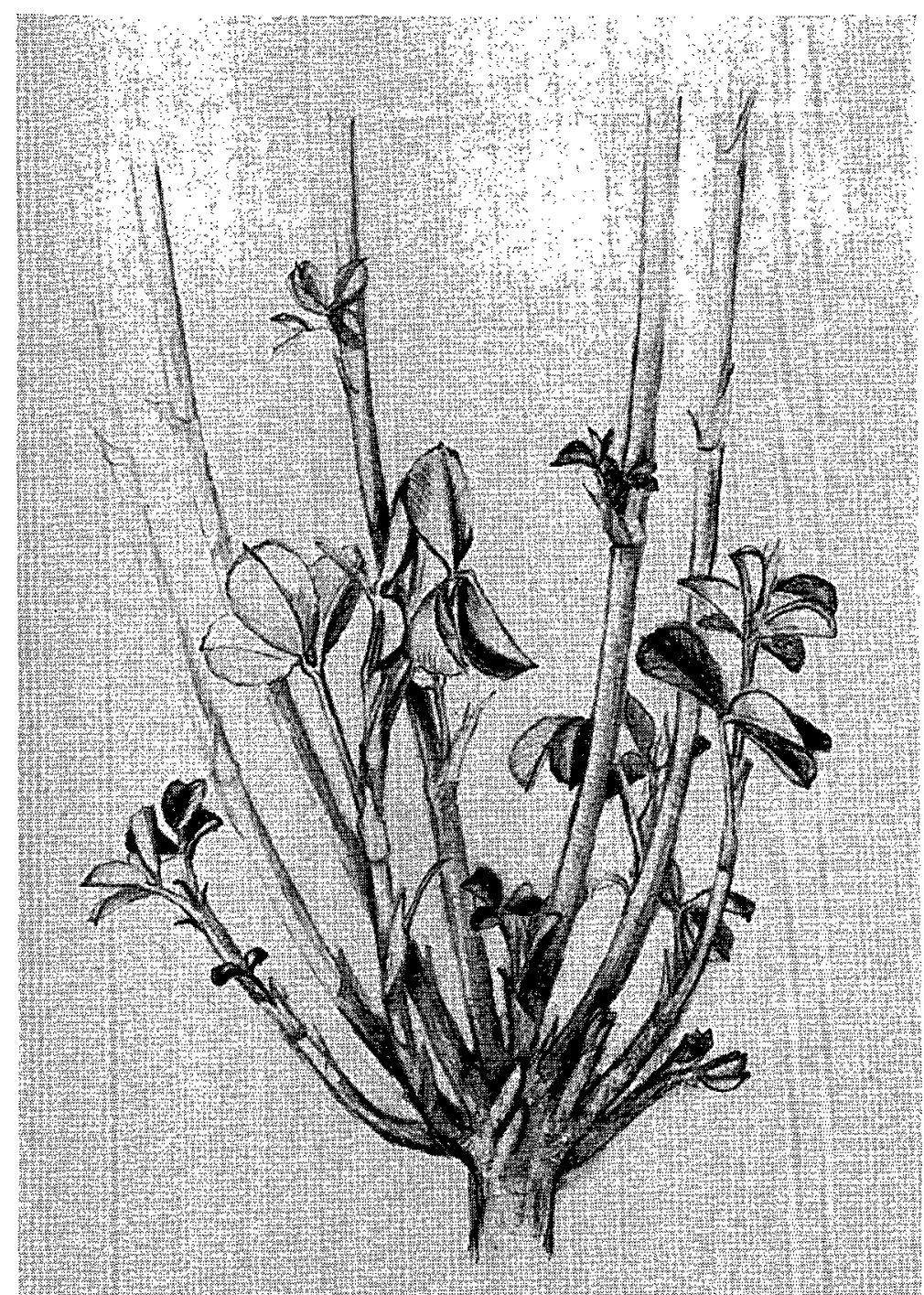

Fig. 1: Basal portion of a ybung lucerne plant showing (a) $M$ ature sterns with shoots arising from axillary positions, and (b) Young shoots and buds growing from the crown. 
of the seedling, those arising in the axil of the two cotyle dons, the simple leaf, and the first few trifoliate leaves, and it is on nodes on these branches that buds may appear. In addition, there appears to be opportunity for further buds to arise, whose position becomes increasingly less clear as the plant matures and which are referred to as adventitious buds (Fig. 1).

The normal pattern of growth appears to be that in the spring a number of buds grow up to form shoots. When these shoots have reached a certain stage, which normally appears to coincide with the appearance of young flowers, a new crop of buds appears on the crown and is ready to take over when the older shoots have been cut. This process is repeated when these new shoots reach the flowering stage. How many generations of buds appear will depend on the strain and the environment. Vernal lucerne in Wisconsin has been shown to produce three per season when left uncut (Smith, 1962).

The implication of this growth rhythm on management is that infrequent cutting at an early flowering stage will give the highest yield of dry matter. If more cuts are taken, and thus the frequency is increased, regrowth will be less rapid, mainly because inadequate numbers of crown buds are ready to elongate. Under these conditions, recovery growth will tend to come initially from buds in the axil of stubble leaves and only after some delay from shoots arising from the crown. In recent experiments it has been found that the axillary shoots from the stubble, although leafier than crown shoots, contribute progressively less to dry matter production as time goes on. However, they could well be instrumental in reducing the harmful effects of cutting at an immature stage on root growth. Whatever the precise source of growth after cutting, it appears to be clear that rapid recovery and subsequent yield will depend on the number of young shoots and well-developed buds which are ready to take the place of the harvested material (Leach, 1968).

\section{INTENSIVE MANAGEMENT}

While it may be desirable to fit lucerne management to the growth rhythm of the plant so as to obtain maximum yield of dry matter, there are circumstances in which this essentially hay-type system has to be abandoned. This is particularly true if dry lucerne meal is the end product. The question thus arises as to how far one may go with impunity in intensifying utilization. Although there is no 


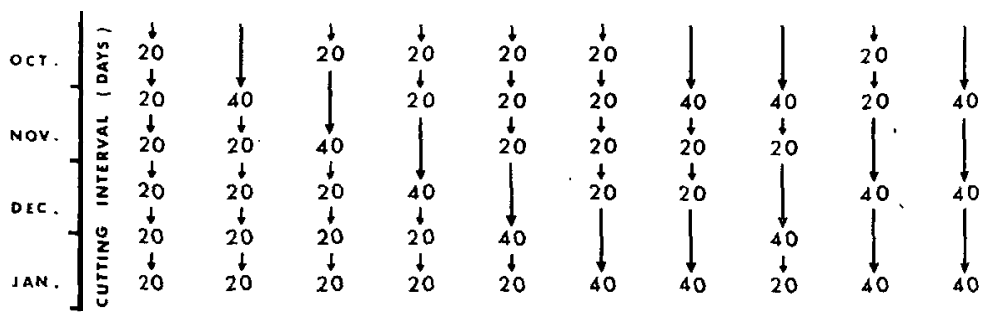

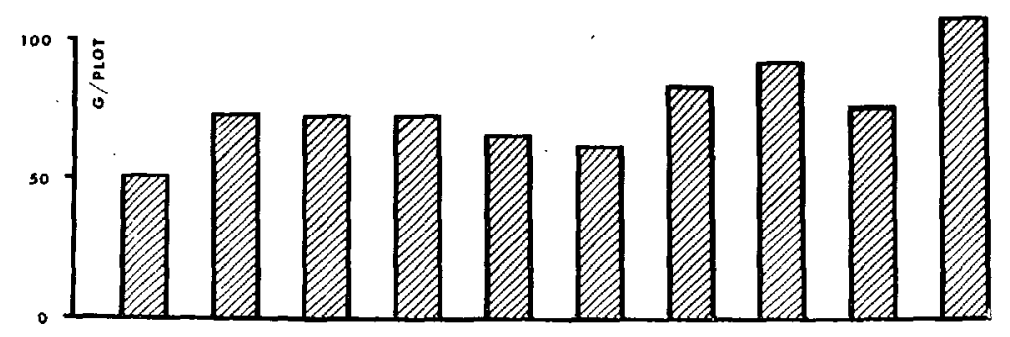

Fig. 2: The effect of 20-day and 40-day cutting intervals in various combinations or dry-matter production of non-irrigated lucerne ( $\mathrm{g}$ per 108/sq. ft plot). (After Steinke, 1963)

single correct answer, the general principles can be derived from an experiment at Lincoln College, in which non-irrigated pure lucerne was subjected to cutting frequencies ranging from six cuts 20 days apart to three cuts at intervals of 40 days. Between these two extremes were treatments incorporating one or two 40-day rest neriods at different times. The results (Fig. 2) show, not unexpectedly, that cutting only three times gave more than twice the yield obtained from six cuts over the same period. A single 40-day interval to allow recovery improved total performance by about $50 \%$ compared with cutting six times, provided that the rest period occurred before the onset of drought conditions from about the middle of December onwards. Two rest periods in the summer were little better than one interjected earlier. However, an alternating system of 20- and 40-day intervals proved to be reasonably successful and approached the yield of the most leniently treated plots.

Although these results were obtained under extreme conditions of management when comparisons rather than actual yield were at stake, they do illustrate that it is possible to increase frequency of cutting, provided that two important principles are observed. The first is that a spell of intensive utilization must be followed by a period in 
which the lucerne is allowed to recover. And, secondly, this recovery period should occur when growth is not limited by dry or other unfavourable conditions. The pre cise length and time of these periods will depend on environmental conditions and in irrigated stands one would suspect that timing is less important than length. Further research on this and other questions is obviously necessary.

In any situation best results are obtained from the harmonious co-operation of all members of a team. Lucerne management is essentially a partnership between the farmer and the plant. The farmer can get the most out of the plant only if he knows it intimately and treats it with the sympathy and understanding it deserves.

\section{REFERENCES}

Keoghan, J. M. 1966: M.Agr.Sc. thesis, Lincoln Coll., Univ. of Canterbury. (Lodged in Lincoln Coll. Library.)

Leach, G. J. 1968: Aust. J. agric. Res., 19: 517-30.

Pritchett, W. L.; Nelson, L. B. 1951: Agron. J., 43: 172-7.

Smith, Dale 1962: Crop Sci., 2: 75-8.

Steinke, T. D. 1963: Ph.D. thesis, Lincoln Coll. Univ. of Canterbury, (Lodged in Lincoln Coll. Library.)

\section{DISCUSSION}

Following a question on the effect of continued short-term defoliations, Langer suggested that there would be a reduced yield from each plant and eventually there would be fewer plants, because some would be so weakened that they would die out. They would probably be replaced by grass if the crop were sown with a grass or with weeds if it were sown alone. Work in Australia suggested that early defoliation in the spring would have a deleterious effect, but Langer stated that no precise information was available in New Zealand. However, it was obvious that early spring growth was important to allow the plant to build up aftei the winter-to provide more leaf and, hence, more carbohydrates. It would therefore be dangerous to remove leaf too early in the spring. This could also apply to the late autumn when a build-up is required for the winter period.

It was observed that it might be better to have more frequent cuts and thus obtain hay of better quality than that derived from more mature growth, even if it meant more frequent re-sowing. Langer agreed that this would provide hay with a higher protein value, but there would be less bulk and a premium for quality might be necessary if the hay were for sale. Following this, it was further stated that more wastage resulted from mature hay and that this would be outweighed by the 
better quality and utilization of the less mature hay. This would offset the lower yield. Langer conceded that very mature hay could lead to much wastage and that higher nutritive value would result from more frequent cuts. It was a matter of obtaining a balance between quality and bulk, particularly if the hay were for sale.

To a question as to whether, with three crops of basal buds in a season, there should not be a longer cycle than the 40-day cutting interval used, Langer replied that the 20. and 40-day intervals were chosen as simple and convenient periods and were based on work outside New Zealand. He thought the best general principle would be to keep as closely as possible to the intervals suggested. 